УДК 502.2

\title{
Stability of the Biosphere \\ and Sustainable Development: a Challenge to Biospherics
}

\author{
Sergey I. Bartsev ${ }^{\mathrm{a}, \mathrm{b} *}$, \\ Andrey G. Degermendzhi ${ }^{a}$ and Antonina B. Sarangova ${ }^{b}$ \\ ${ }^{a}$ Institute of Biophysics SB RAS \\ Federal Research Center \\ "Krasnoyarsk Science Center SB RAS", \\ 50/50 Akademgorodok, Krasnoyarsk, 660036, Russia \\ ${ }^{b}$ Siberian Federal University \\ 79 Svobodny, Krasnoyarsk, 660041, Russia
}

Received 27.02.2017, received in revised form 04.05.2017, accepted 07.05.2017

The central point of the concept of sustainable development proposed for overcoming unwelcome trends in the development of the environment - "The right to development must be fulfilled so as to equitably meet developmental and environmental needs of present and future generations" contains certain conflict. The bottom line is that modern human beings cannot live without the infrastructure that pollutes the environment, and the future generations will not be able to live without this environment. The conflict can be mitigated by switching to the optimal infrastructure, which will maintain human impact on regional ecosystems at levels that fall within the range of their resilience. To achieve this goal, the following objectives must be fulfilled: 1) to develop methods for evaluating "resilience" of local ecosystems and the biosphere; 2) to develop technologies for production of goods that have the lowest possible environmental impact in all stages of their lifecycle: production, use, and disposal; 3) to develop methods for designing systems of optimal environmental management at regional levels and formulate an adequate optimality criterion. Difficulties arising in achieving these objectives have been illustrated by using rather simple examples. In some instances, the ecosystem shows a threshold response to upsetting impact, and on the way to the threshold, there may be no indications of the pending disaster. The possibility of the threshold response to the gradually increasing impact - a rise in the greenhouse gas concentrations - has been shown by using a low-dimensional model of the biosphere. An example of electric vehicles is used to show that if, by analogy with the input-output model (IOM) developed by W. Leontief, one takes into account the direct and indirect ecological damage caused by production, use, and disposal of the product, the resulting assessment of the environmental harm may be drastically different from the

(c) Siberian Federal University. All rights reserved

* Corresponding author E-mail address: bartsev@yandex.ru 
claimed one. Simple examples demonstrate dramatic dependence of the configuration of the optimal infrastructure on optimality criteria used by decision makers.

Keywords: problems of sustainable development, stability of ecosystems and the biosphere, optimal nature management.

Citation: Bartsev S.I., Degermendzhi A.G., Sarangova A.B. Stability of the biosphere and sustainable development: a challenge to biospherics. J. Sib. Fed. Univ. Biol., 2017, 10(2), 134-152. DOI: 10.17516/1997-1389-0018.

\title{
Стабильность биосферы и устойчивое развитие: вызов биосферике
}

\author{
С.И. Барцев ${ }^{\mathrm{a}, \boldsymbol{0}}$, \\ А.Г. Дегерменджи ${ }^{\mathrm{a}}$, А.Б. Сарангова ${ }^{\tilde{0}}$ \\ ${ }^{a}$ Институт биофизики СО РАН \\ Федеральный исследовательский иентр \\ «Красноярский научный центр СО РАН» \\ Россия, 660036, Красноярск, Академгородок, 50/50 \\ ${ }^{6}$ Сибирский федеральный университет \\ Россия, 660041, Красноярск, пр. Свободный, 79
}

Центральный пункт концепщии устойчивого развития, предложенной для преодоления негативных тенденций в состоянии окружающей среды - «Сохранение среды обитания и природных ресурсов для следующих поколений при обеспечении хорошего качества жизни ныне живущих поколений», содержит в себе зерно конфликта. Проблема в том, что человечество не может существовать без инфраструктуры, загрязняющей среду обитания, без которой, в свою очередь, не смогут существовать будущие поколения. Остроту конфликта можно ослабить, если перейти к оптимальной инфраструктуре, обеспечивающей поддержание уровня антропогенного воздействия на региональные экосистемы в пределах их устойчивости. Для этого нужно решить следующие задачи: 1) разработать методы оценки “эластичности” локальных экосистем и биосферы; 2) развить технологии, производящие продукцию с минимальным экологическим воздействием на всех этапах ее жизни: производство, эксплуатация и утилизаиия; 3) разработать методы проектирования структур оптимального природопользования на уровне регионов с формулировкой адекватного критерия оптимальности. Сложности, возникающие при решении этих задач, проиллюстрированы на достаточно простых примерах. Показано, что отклик экосистемы на возмущающее воздействие может иметь пороговый характер, причем по мере приближения $\kappa$ порогу какие-либо признаки надвигающейся катастрофы могут отсутствовать. Возможность порогового ответа на плавно нарастающее воздействие - рост концентрации парниковых газов - показана на малоразмерной модели биосферы. На примере электрических 
автомобилей продемонстрировано, что если по аналогии с моделью межотраслевого баланса, разработанной В.В. Леонтьевым, учитывать прямой и косвенный экологический ущерб, возникающий при производстве, эксплуатащии и утилизации продукта, то полученная оценка экологического вреда может кардинально отличаться от декларируемой. На простых примерах показано, что конфигурачия оптимальной инфраструктуры существенно зависит от критериев оптимальности, которыми руководствуются лица, принимающце решения.

Ключевые слова: проблемы устойчивого развития, устойчивость экосистем и биосферы, оптимальное природопользование.

\section{Introduction}

The existence of unfavorable or even catastrophic trends in the development of the environment has been recently recognized by various experts and leaders of most of the countries and international organizations (IPCC, 2014), as evidenced by the Declaration on Environment and Development signed at the Conference in Rio-de-Janeiro in 1992 (Rio, 1992) and subsequent international agreements.

The concept of sustainable development founded on 27 principles has been proposed as a blueprint for action. Let us now take a look at the problems associated with implementation of this concept. First, we should examine the principles and see whether they are accurate and balanced. Let us take the first principle as an example: "Human beings are at the centre of concerns for sustainable development. They are entitled to a healthy and productive life in harmony with nature."

This sounds life-affirming, and the ultimate goal appears quite definite. Yet, the questions then arise: Can human beings attain harmony with nature? And if yes, what will it look like? The first question, however, that we should answer is "Have human beings ever lived in harmony with nature?"

The primate - the ancestor of humans, as well as all other organisms, was originally an integral part of the biosphere and was regulated by it. All living organisms in nature interact with other organisms and the environment in a balanced way, occupying their niches, which have been developed by evolution, in this system of interactions: they consume something and they are consumed. This is what should be called ecological harmony. Unbalancing of this interaction causes environmental disasters such as outbreaks of the Siberian silk moth, which leave behind almost dead parts of taiga, similar to those destroyed by fire.

However, as one of the branches of primates was evolving into the human, this branch began to break away from the rule of ecological laws, creating "a second nature". Humans stayed within the biosphere, but impetuously expanded their ecological niche, simultaneously destroying the ecological niches of their neighboring species or eliminating competing or edible species. Humans differ from other "ecologically loyal" species in that they surround themselves with "a second nature" - infrastructure. Even in ancient times, this resulted in local environmental disasters.

The weight of evidence suggests (with a higher or lower level of certainty) that the Sahara resulted from slash-and-burn and clearcutting factors causing rivers in that region to dry. Overgrazing has led to erosion and desertification of the formerly fertile soil. The proverb "Goats have eaten Greece" has been known since ancient times. In Greece, goat breeding caused elimination of woody plants, and goats' hooves 
have trampled the land. In the ancient times, soil erosion in the Mediterranean was 10 times more severe on ameliorated areas. In other regions, deforestation along riverbanks reduced the formerly navigable waters to shallow arroyos. Construction of powerful irrigation systems resulted in water and salt imbalance, leading to formation of vast saltmarshes.

Thus, we have to admit that human beings have almost never lived in harmony with nature. The root cause of environmental problems is that humans have strived to solve current issues ignoring the consequences of their actions. Hence, the ultimate goal presented in Principle 1 has not been described with sufficient detail, and the few examples of harmonic coexistence of humans with nature over long periods of time in archaic communities are not applicable to the technological and populous society.

\section{Infrastructure-biosphere conflict and possible ways of its elimination}

The necessity to consider the consequences while solving the immediate problems is proclaimed in Principle 3 of the Declaration on Environment and Development: "The right to development must be fulfilled so as to equitably meet developmental and environmental needs of present and future generations."

This principle sounds quite reasonable, but it contains certain conflict, whose resolution requires special effort. A civilized human being needs not only clean air, water and food but also such fruits of civilization as housing, heating, pharmaceutical drugs, cars, video, etc. However, the infrastructure that provides them has an unwelcome effect on the biosphere and climate (Fig. 1A). The bottom line is that modern human beings cannot live without the industrial infrastructure that pollutes the environment, and the future generations will not be able to live without the environment that is now being destroyed by industry.

The ideal way to resolve this conflict is to change over to closed-loop technological cycles, including complete waste recycling (to primary products) (Fig. 1B). Unfortunately, development of suitable technologies would require enormous expenditures, resulting in a considerable increase in the cost of the products. Market economy will not allow closed-loop cycles to be introduced in commercial production.

Yet, there is a realistic approach to environmental management that could mitigate, if not eliminate, infrastructure-biosphere conflict. This approach consists in decreasing humaninduced impact and developing an optimal infrastructure, which would maintain the level of human impact on regional ecosystems within their resilience limits, i.e. within the limits of their capacity to compensate for the external destructive effects.

Listed below are the objectives that should be achieved to implement the proposed approach

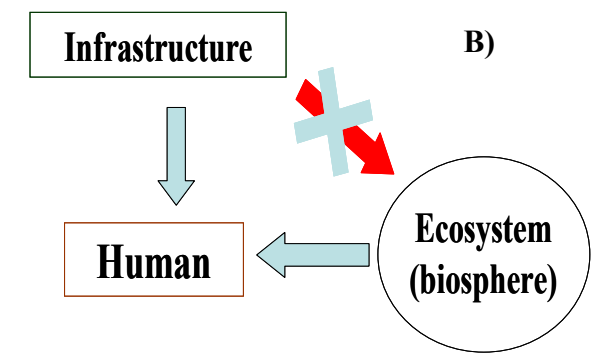

Fig. 1. The genuine collision of fulfilling human needs (A) and a drastic but unrealistic way to resolve it (B) 
to settling the abovementioned conflict. The objectives are listed in order of decreasing scientific "purity":

1) to develop methods for evaluating "resilience" of local ecosystems and the biosphere;

2) to develop technologies for production of goods that have the lowest possible environmental impact in all stages of their lifecycle: production, use, and disposal;

3) to develop methods for designing systems of optimal environmental management at regional levels and formulate an adequate optimality criterion.

The first objective is a purely scientific task, while the second also contains a mandatory economic aspect and the third, in addition to economics, includes choice criteria, which are determined by the value system of decision makers.

Interestingly, the above objectives (probably incompletely listed) belong in the activity called engineering, which is aimed at creating something new rather than studying the surrounding world theoretically. The academically worded objective, Objective 1, although of fundamental importance, plays a subordinate role. Achievement of this objective will correspond to the development of the theory of strength of materials in engineering, without which none of the more or less vitally important constructions or devices has been created. That is why the specific environmental (or even biospheric) activity aimed at attaining these objectives can be properly called biospherics (Pechurkin, 1994) - a nearly forgotten name, created by analogy with bionics, electronics, and genetics.

Difficulties arising in achieving these objectives have been illustrated by using rather simple examples.

\section{Objective 1. Evaluating "resilience" of local ecosystems and the biosphere}

Let us examine the difficulties on the way to achieving Objective 1. No direct experiments can be conducted to estimate the limits of resilience of the ecosystem, as such experiments would inevitably destroy the ecosystem. The only possible way to reach this objective is to construct and investigate mathematical models of ecosystems. Consider a very simple model of human impact on the ecosystem. Suppose there is an ecosystem, e.g. a water body, which is characterized by the biomass of its biota, i.e. the biomass of all living organisms constituting it (Fig. 2).

A factory discharges its effluents into this ecosystem; these effluents will be collectively called a pollutant and denoted with letter $S$. This pollutant is fed into the ecosystem at a rate of $V_{0}$. This pollutant may be slowly degraded through purely chemical processes that are not related to living organisms at a rate proportional to pollutant concentration $-k_{x} S$. The same

\section{Factory}

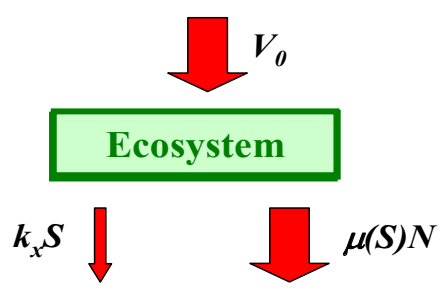

Fig. 2. A scheme of pollutant fluxes in the ecosystem 
pollutant, however, may be consumed relatively quickly by microorganisms - components of the biota, which will then be consumed by other organisms - components of the ecosystem. Some microorganisms can even consume phenol and crude oil. The rate of consumption of the pollutant depends on its concentration and biomass of the biota $-\mu(S) N$, where $N$ is biota biomass.

The following equation describes pollutant dynamics:

$$
\dot{S}=V_{0}-k_{x} S-\mu(S) N .
$$

The equation describing biomass dynamics can be written as follows:

$$
\dot{N}=y \mu(S) N-k_{d} N,
$$

where $y$ is coefficient showing what portion of the substrate consumed (pollutant) is expended on synthesis of biomass, $k_{d}$ is mortality of biota.

The type of substrate concentration dependence of biota growth rate is of great importance. In general, as substrate concentration increases, the growth rate first increases, then slows down, and, finally, as substrate concentration increases further, the growth rate begins to decline. This is called substrate inhibition, for which jam is a common example. Sugar is a good substrate for microorganisms, but large quantities of sugar inhibit their growth, and sugar becomes a preserving agent.

In mathematical terms, substrate inhibition can be written as follows:

$$
\mu(S)=\frac{\mu_{\max } S}{K_{m}+S+\frac{S^{2}}{K_{i}}},
$$

where $\mu_{\max }$ is maximal rate of substrate consumption; $K_{m}$ is the Monod constant; and $K_{i}$ is inhibition constant.

The curve of concentration dependence of the growth rate (substrate consumption) is shown in Fig. 3. Figure 3 also shows linear dependence of the substrate influx rate, taking into account substrate chemical decomposition. These lines intersect at stationary points, at which the rate of change in the total substrate concentration is equal to zero.

By investigating this model using computational experiments, one can see very important features of ecosystem response to the external impact. Figure 4 shows that if the pollutant discharge rate is below some critical value, pollutant concentration in the system is maintained at a low level, i.e., the ecosystem purifies itself of the pollutants. If the discharge rate is even a hundredth of percent higher than the critical value, the system undergoes dramatic

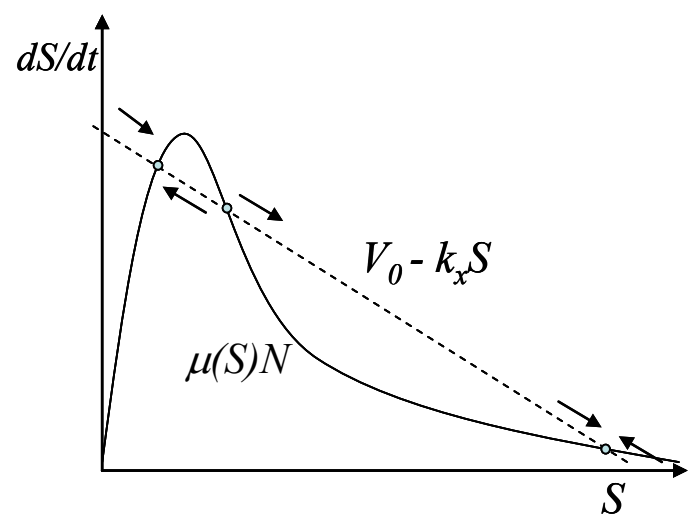

Fig. 3. Stationary points in the pollutant-biota system (see details in the text) 

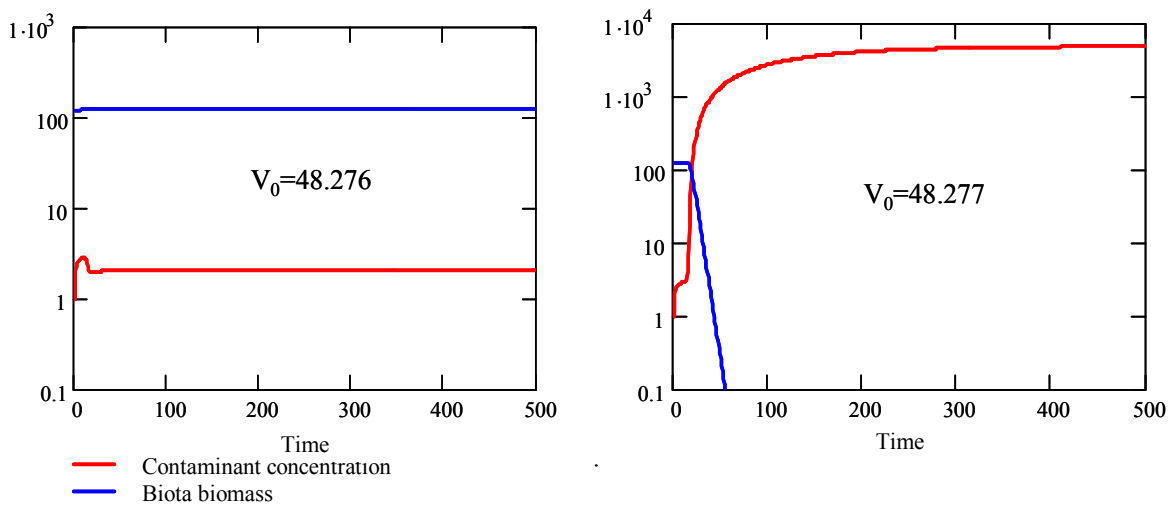

Fig. 4. Threshold response of biota to an insignificant increase in pollution rate $\left(\mathrm{V}_{0}\right)$

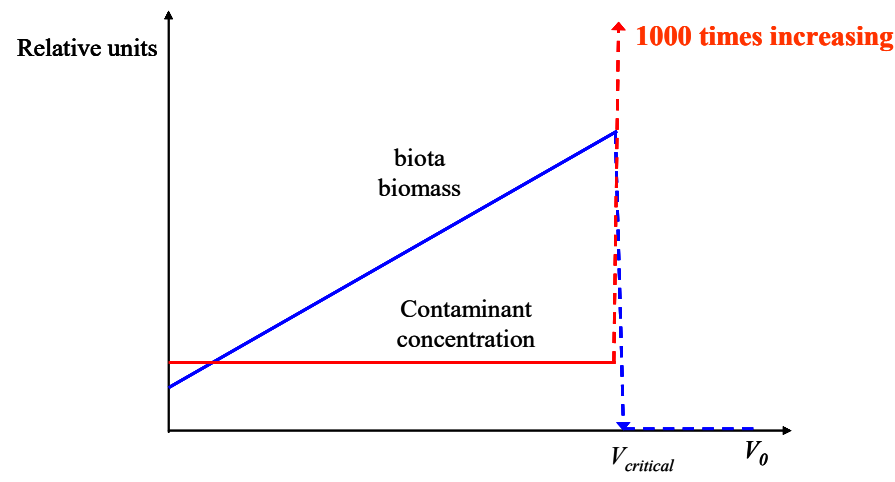

Fig. 5. Response of biota to various pollutant discharge rates

changes: pollutant concentration increases by a factor of one thousand while the amount of biomass drops to zero. An environmental disaster takes place.

Figure 5 shows the relationship between pollutant concentration and biota biomass and pollutant discharge rate. The most important in this graph is not that the state of the system changes dramatically and almost irreversibly but that the pending disaster has occurred unexpectedly, without warning. In fact, until the discharge rate reached its most critical value, pollutant concentration in the environment had remained constant, causing no concern, and the biomass had been even increasing, which could be (mistakenly) interpreted as an improvement in the state of the ecosystem.
The model proposed above is certainly very simple, and it does not take into account some of the essential properties of a real ecosystem. In a more realistic model of the ecosystem, some warnings are given, but they are very unobtrusive, and the curve showing the response of the system to the increase in the discharge rate cannot predict when the disaster will occur. This suggests an important conclusion that construction of valid mathematical models is an indispensable condition of rational environmental management, enabling both the existence of the industrial infrastructure and preservation of ecosystems.

Limits of resilience should be also determined for the biosphere-climate system as an integral system that is subjected to the ever-increasing 
human impacts, which include greenhouse gas emissions and environmental pollution.

However, an obstacle in the path of constructing valid models of local ecosystems and, in particular, the biosphere is enormous complexity of these systems - the so-called curse of dimensionality. A possible solution to this problem situation is based on Principle 15 (Precautionary principle) of the Declaration on Environment and Development: "In order to protect the environment, the precautionary approach shall be widely applied by States according to their capabilities. Where there are threats of serious or irreversible damage, lack of full scientific certainty shall not be used as a reason for postponing cost-effective measures to prevent environmental degradation."

This principle suggests that we must find and consider the global scenarios that predict the gravest consequences. The constructive interpretation of the precautionary principle may be termed as "the worst-case scenario principle" (Bartsev et al., 2008).

In accordance with this principle, if there is uncertainty in evaluation of parameters, we must choose the worst combination of the values of these parameters, which, nevertheless, stay within the range of confidence intervals. Moreover, if there are doubts about the effectiveness of any natural mechanism compensating for the negative dynamics, we must ignore this mechanism in our models. Thus, consistent use of the worst-case scenario principle results in construction of simplified models.

We should now determine the worstcase scenario for global dynamics. Traditional complex distributed models of general circulation are aimed at constructing the most probable scenario of biosphere and climate dynamics. However, since the distribution of probabilities of possible scenarios is unknown, knowing the most probable scenario is useless for making practical decisions. It is very important to know the conditions under which the worstcase scenario can come true. To illustrate, let us look at a fan of possible scenarios of the increase in atmospheric carbon dioxide concentration (Fig. 6). Obviously, the worst-case scenario is not the scenario corresponding to the uppermost but smooth curve but rather the scenario described by the rapidly rising curve, which corresponds to the self-accelerating process.

As suggested by Principle 15 of the Declaration, we must decide whether this selfaccelerating process can really take place. Such self-accelerating processes are typical for systems with positive feedbacks. Having

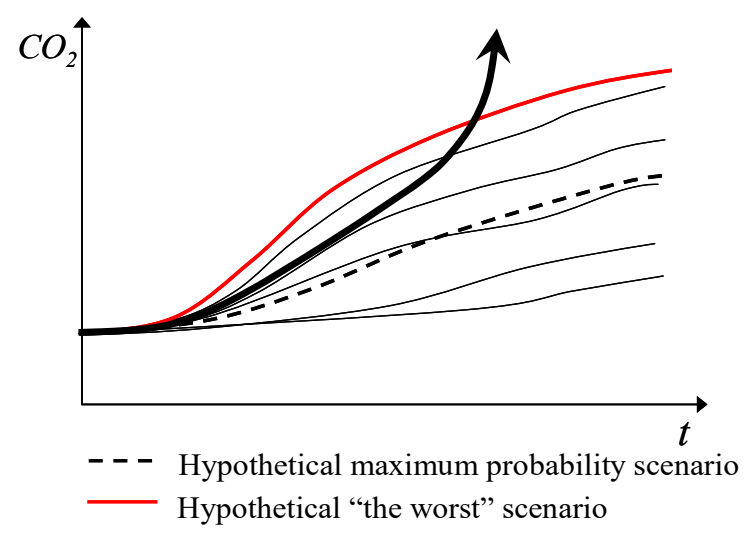

Fig. 6. An illustration of which of the possible scenarios is the worst-case one 


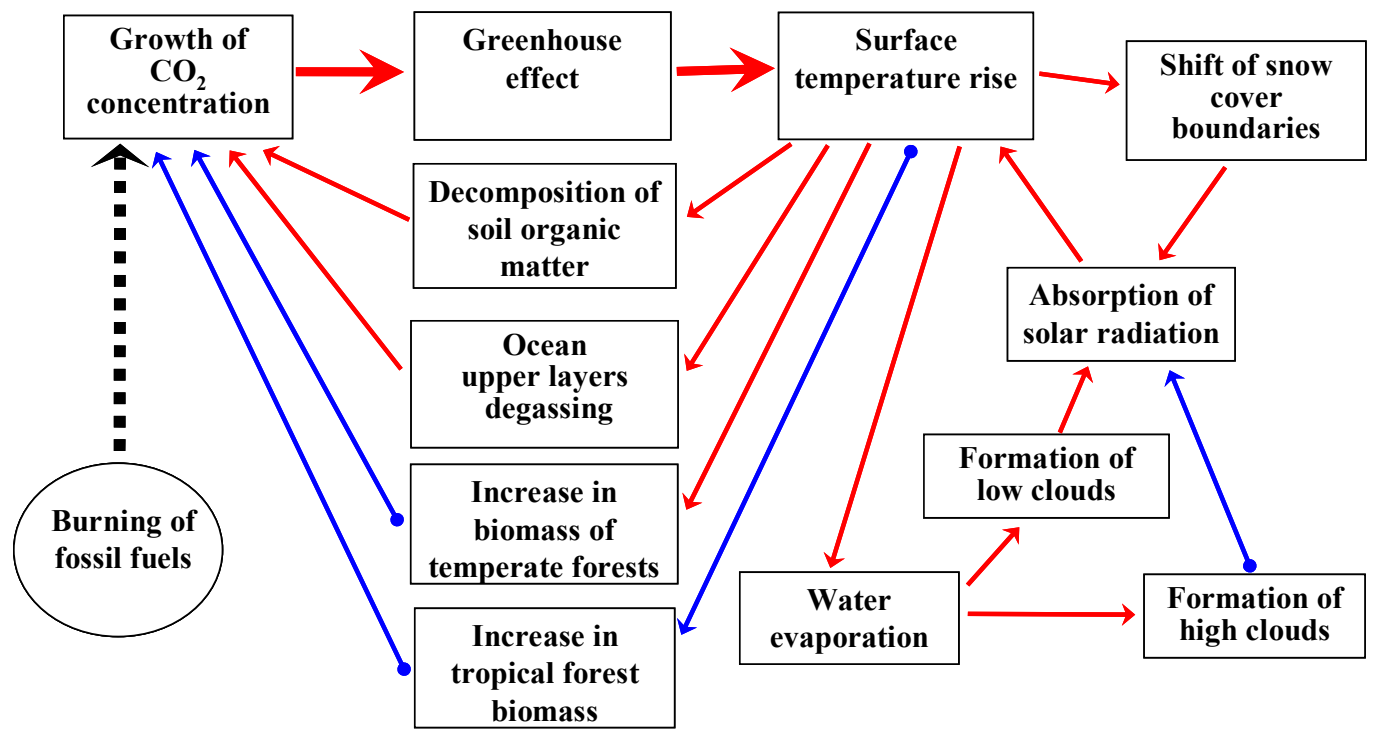

\section{4- - . - - external influence $\longleftarrow$-positive effect $\longleftrightarrow$ - negative effect}

Fig. 7. A diagram of the most evident feedbacks in the biosphere

analyzed the system of possible feedbacks in the biosphere - climate system (BCS), we obtain the following (known to be incomplete) diagram of feedbacks (Fig. 7), which gives an idea of the complexity of the system.

Following the worst-case scenario principle, we have chosen the feedbacks that have the shortest characteristic times, i.e. the feedbacks that can give rise to quick changes in the BCS (Fig. 8).

The global model shown in Fig. 8 consists of five compartments between which carbon dioxide is exchanged: the atmosphere, land plants, the corresponding dead organic residues, and surface and deep layers of the ocean (Bartsev et al., 2012a). These compartments are interrelated through processes of growth, death, and decomposition of biomass and exchange of $\mathrm{CO}_{2}$ between the atmosphere and the ocean. The model also contains the anthropogenic carbon source, which upsets the carbon balance of the system. The set of equations constituting the model has the following form:

$$
\begin{aligned}
& \frac{\mathrm{d} A}{\mathrm{~d} t}=S(y, T(A))+C_{\mathrm{a} \_ \text {up }} B M_{\mathrm{out}}(A)- \\
& -P(x, A, T(A))-C_{\mathrm{a} \_ \text {down }} A M_{\text {in }}(A)+\text { fuel }(t), \\
& \frac{\mathrm{d} x}{\mathrm{~d} t}=P(x, A, T(A))-D(x), \\
& \frac{\mathrm{d} y}{\mathrm{~d} t}=D(x)-S(y, T(A)), \\
& \frac{\mathrm{d} B}{\mathrm{~d} t}=\left[C_{\mathrm{a} \_ \text {down }} A M_{\mathrm{in}}(A)+C_{\mathrm{d} \_ \text {up }} U\right]- \\
& -\left[C_{\mathrm{f}_{\_} \text {down }} B+C_{\mathrm{a} \_ \text {up }} B M_{\text {out }}(A)\right], \\
& \frac{\mathrm{d} U}{\mathrm{~d} t}=C_{\mathrm{f} \_ \text {down }} B-C_{\mathrm{d} \_ \text {up }} U .
\end{aligned}
$$

The first equation describes the change in the amount of carbon in the atmosphere, the second - in the vegetation biomass, the third - in dead organic matter, the fourth - in surface ocean layers, and the fifth - in deep layers of the ocean. The detailed description and assumptions providing the basis for the model can be found elsewhere (Bartsev et al., 2008; Degermendzhi et al., 2008); thus, here we only describe the types of functions used in the equations. 


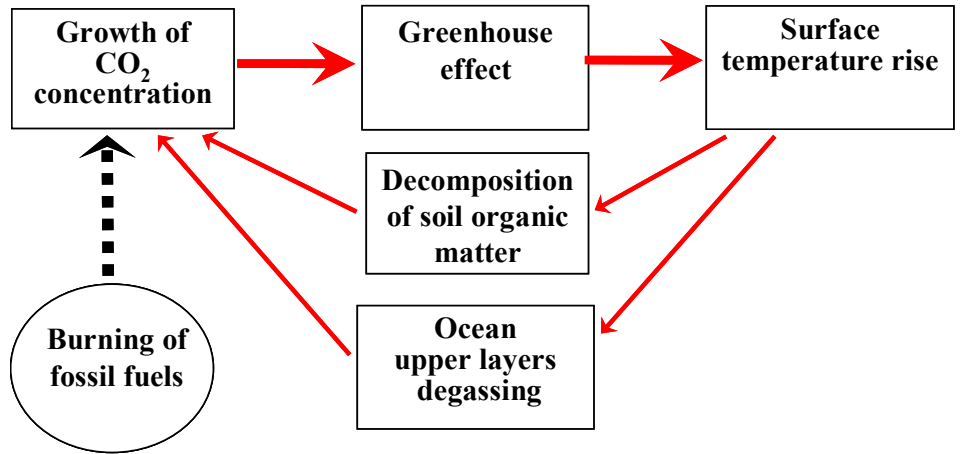

Fig. 8. A diagram of the quickest feedbacks in the biosphere

The function of the growth rate of plant biomass (GtC/year) has the following form:

$$
\begin{gathered}
P(x, A, T)=V_{p} \cdot x \cdot\left(x_{\max }-x\right) \\
\cdot V(A) \cdot f_{p}(T(A)),
\end{gathered}
$$

where $x$ is the amount of carbon in the biomass of the plant compartment (GtC); $A$ - atmospheric carbon (GtC); $T$ - average annual global surface temperature; $V_{p}$ - the scale factor $(1 /(\mathrm{GtC} /$ year $))$; $x_{\max }$ - the limited amount of biomass that depends on the limit of the density of plant cover.

Function $V(A)$ describes the growth of biomass in relation to the atmospheric concentration of $\mathrm{CO}_{2}$ in the form of the wellknown Monod function:

$$
V(A)=\frac{A}{K_{A}+A} .
$$

The empirical dependence of the rate of plant biomass growth on temperature $\mathrm{T}$ and the maximum temperature $T_{\max }$ is as follows:

$$
f\left(T, T_{\max }\right)=T^{d}\left(T_{\max }-T\right) .
$$

The empirical dependence of the growth of average global surface temperature on the $\mathrm{CO}_{2}$ concentration was derived from the published data (Gifford, 1993):

$$
T(A)=T_{o}+T_{\mathrm{del}} \cdot \log _{2}\left(\frac{A}{A_{0}}\right)
$$

where $A$ is the current amount of carbon in the atmosphere, $A_{o}$ is the amount of carbon in the atmosphere at the time of measuring the average surface temperature $T_{o}$, which is now equal to $15.5 ; T_{d e l}$ is the climate sensitivity.

The form of function fuel $(t)$ depends on the source of $\mathrm{CO}_{2}$ external to the biosphere that disrupts the closed loop of the carbon cycle. For the prediction of future dynamics, this function is determined by the possible scenario of burning fossil fuel.

The extinction rate of biomass ( $\mathrm{GtC} /$ year) is written in a simple form as follows:

$$
D(x)=V_{d} \cdot x,
$$

where $V_{d}$ is a scale factor; $x$ is the amount of carbon (Gt) in the biomass.

The rate of soil respiration (decomposition of dead organic matter) and $\mathrm{CO}_{2}$ emissions in the atmosphere is described with the following function:

$$
S(y, T)=V_{\mathrm{s}} \cdot y \cdot f_{\mathrm{M}}(T),
$$

where $V_{S}$ is a scale factor; $y$ is the amount of carbon in dead biomass $(\mathrm{Gt}) ; f_{M}(T)$ is the function of type (8) that expresses the temperature dependence of soil respiration, but for larger values of maximum temperature.

In Eq.4 the term $C_{a_{-} d o w n} A M_{\text {in }}(A)$ describes the absorption of carbon dioxide with the surface 
layer of the oceans, and the term $C_{a_{-} u p} B M_{\text {out }}(A)$ emission of carbon dioxide from the ocean surface to the atmosphere. Variable coefficients $\mathrm{M}_{\mathrm{in}}(A)=e^{-0.03\left[T(A)-T_{0}\right]}$ and $\mathrm{M}_{\text {out }}(A)=e^{0.03\left[T(A)-T_{0}\right]}$ describe the physical phenomenon of the decrease in gas solubility in the liquid at higher temperatures. These coefficients are obtained by simple empirical approximation of data on the concentration of $\mathrm{CO}_{2}$ in water at different temperatures (Kondratiev and Krapivin, 2004). The term $C_{d_{-} u p} U$ describes upwelling and $C_{f_{-} \text {down }} B$ downwelling.

Various evaluations of the carbon pool in the atmosphere and land compartments along with flows between them were presented in a number of works (Brovkin et al., 2002; Brovkin et al., 2004; IPCC, 2001; Kondratiev and Krapivin, 2004; Semenov, 2004; Trenberth at al., 1996). In accordance with the worst-case scenario principle, the initial values of model parameters were chosen as $850 \mathrm{GtC}$ in plant biomass and $1100 \mathrm{GtC}$ in sediment organics.

In Eq.5, Eq.9, and Eq.10, scale factors were only set to make biomass growth and soil respiration equal to $55 \mathrm{GtC} /$ year as estimated in the abovementioned papers. Without an anthropogenic source of $\mathrm{CO}_{2}$, the model stays in the stationary state, which corresponds to biosphere and climate parameters at the end of the twentieth century.

To calculate possible scenarios of the development of the biosphere, we used the scenario of burning of fossil fuels denoted with A2 in the IPCC classification (IPCC, 2007).

The purpose of conducting computational experiments was to estimate the conditions under which catastrophic scenario comes true and to determine the "point of no return" corresponding to these conditions, i.e. the point in time after which the system will collapse even if human-induced carbon emissions stop completely. To illustrate the dynamics of the biospheric model, an artificial situation where $\mathrm{CO}_{2}$ emission is completely stopped after 100 years of A2 scenario realization (IPCC, 2007) was considered. Results of the computational experiment at different values of the climate sensitivity $\left(T_{d e l}\right)$ are shown in Fig. 9.

Computer experiments expectedly show that the greater the value of the climate sensitivity, the greater impact of anthropogenic influence to the
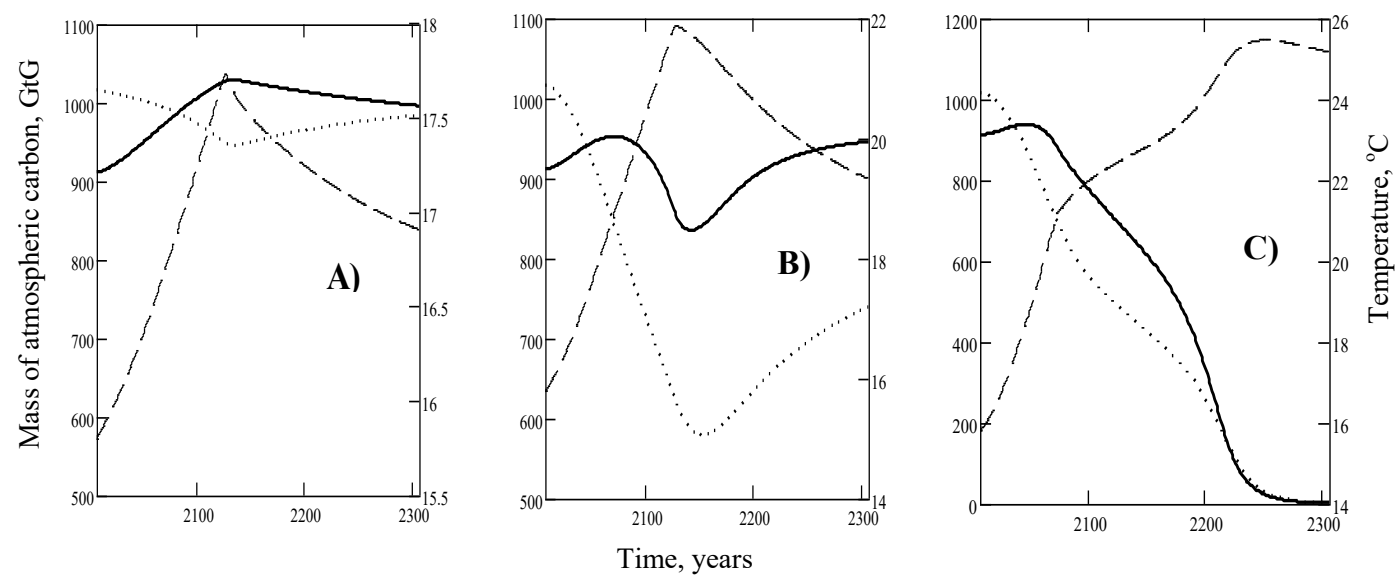

Fig. 9. Scenarios of biosphere dynamics at different values of the climate sensitivity $T_{d e l}$. The graphs correspond to the following values of $T_{d e l}$ : (A) $-2{ }^{\circ} \mathrm{C} ;(\mathrm{B})-4.5^{\circ} \mathrm{C} ;(\mathrm{C})-6{ }^{\circ} \mathrm{C}$. In the latter case $(\mathrm{C})$, the date of irreversibility is 2073. On the graph, the solid line describes the dynamics of the biomass, the dotted line indicates the dead organic matter, and the dashed line indicates the temperature change 
biosphere. It is shown that at $T_{d e l}=6{ }^{\circ} \mathrm{C}$ the time to the irreversibility point becomes less than 100 years, which leads to starting the run off regime in the biosphere.

Summarizing the possible properties of local ecosystems and the biosphere illustrated above, we can conclude that the threshold response of ecosystems and the entire biosphere, which is aggravated by the absence of any clear warnings of the approaching limit of stability, is a key challenge to biospherics.

\section{Objective 2. Providing}

\section{the lowest environmental impact over lifecycle of goods}

Objective 2 corresponds to the problem of developing economically and environmentally optimal waste treatment systems. The economic aspect emerges because treatment of wastes, including old and broken devices and consumer goods, consumes power and resources, which cost money.

All commercially manufactured products and production plants have limited lifecycles.
When they are not functional any more, products and production plants must be treated as waste and disposed of. As production and consumption material cycling has become prominent against the background of biospheric and environmental (regional) material cycles, the condition of minimizing environmental impact of industrial processes and commercial products acquires increasing importance.

Waste treatment may occasionally occur spontaneously, through natural chemical and biological processes. In most cases, however, alleviation of environmental impact consumes additional materials, power, and labor. It seems that larger expenditures could nullify the damage done by waste treatment to the environment. Unfortunately, these expenditures also produce adverse effects on the environment. There is an obvious contradiction here: the more effort we put into waste treatment, making it more thorough and complete, the greater environmental impact we produce (see Fig. 10) (Bartsev et al., 2012b).

In order to optimize environmental management, one has to choose and introduce the

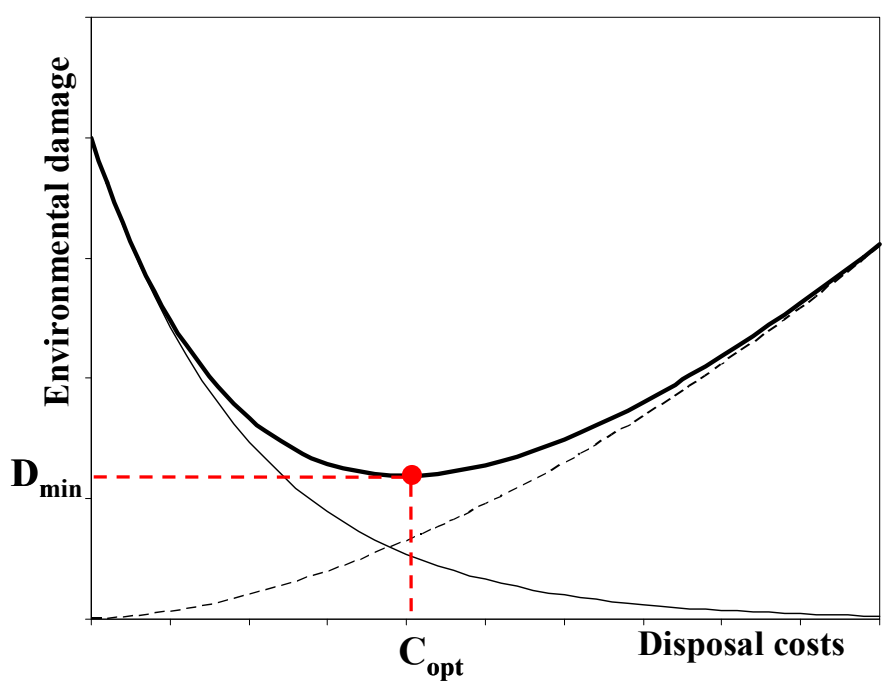

Fig. 10. A conditional graph illustrating the presence of the minimum of environmental damage. The thin solid line denotes residual environmental damage caused by the product vs. waste processing costs; the dashed line denotes the damage due to waste disposal; the thick solid line denotes the total environmental damage. $\mathrm{D}_{\min }-$ minimum possible level of environmental damage caused by the product, $\mathrm{C}_{\mathrm{opt}}$ - optimal waste processing costs 
technologies that would yield goods producing the lowest total damage to the environment in all their life stages, with economic costs remaining at the same level. If economic costs are different, optimal decisions in environmental management can only be achieved by resolving the problem of introducing the "cost" of environmental damage, expressed, e.g., as the "price" of a human life. This very difficult task is, however, beyond the scope of this consideration.

To achieve optimization of environmental management, one needs to find a relationship between the ultimate contamination and costs of production, use, and disposal of goods. It would be natural to assume that production of the waste by the goods, similarly to any other production, is proportional to the cost of the corresponding resources and depends on the technology used. Hence, the problem of determining the total environmental damage can be reduced to the problem of total inputs, which can be solved by methods similar to the input-output model (IOM) developed by W. Leontief (1973).

As noted above, total cost assessment must include costs of production, use, and disposal of a given product. Unfortunately, environmental advantages of goods are sometimes evaluated taking into account only their usage cost, as in evaluating the environmental advantages of electric vehicles vs. internal combustion engine vehicles in accordance with European standards (Eberhard, 2009).

As a parameter for comparison of goods, we propose introducing a common specific environmental cost of the usage of the $l$-th product (Bartsev et al., 2012b):

$$
R_{l}^{S}=\sum_{i} a_{i}\left(\frac{1}{T_{l}}\left(r_{0}^{i}+r_{U}^{i}\right)+R_{l}^{i}\right),
$$

where $r_{0}^{i}$ denotes input cost of resources for the production; $r_{U}^{i}$ is disposal cost; $R_{l}^{i}$ is damage caused by the product usage per unit time; $T_{l}$ is the lifetime of the product; $a_{i}$ are coefficients of environmental damage, $i-s$ represent different types of environmental harm.

By replacing the bracketed expression with one symbol

$$
S_{l}^{i}=\frac{1}{T_{l}}\left(r_{0}^{i}+r_{U}^{i}\right)+R_{l}^{i},
$$

where vector $S_{l}^{i}$ characterizes total inputs for the production, usage, and disposal of the product per unit time, we can express the specific environmental cost of the product as follows:

$$
R_{l}^{S}=a_{i} S_{l}^{i}
$$

If, however, only direct inputs of resources $S_{l}^{i}$ for the $l$-th product are taken into account, their environmental impact will be clearly underestimated. All input resources were produced by industries that also consumed resources and caused environmental damage. This sequence should be continued until we reach primary resources - minerals and energy sources (Fig. 11). However, mineral resources and energy sources can only be developed using products of engineering and processing industries. Thus, the complete structure of maintenance costs of the product will be represented by an infinite number of decaying cycles.

In practice, one can either move to the limit, as it is done in the IOM, or confine oneself to a preset accuracy level, taking into account only indirect inputs of the corresponding order, as we do in this study.

Let us call the set ${ }^{1} \mathrm{~S}_{1}^{\mathrm{i}}$ of resources needed for production $S_{l}^{i}$ as the vector of the first order indirect inputs. Values of ${ }^{1} \mathrm{~S}_{1}^{\mathrm{i}}$ components can be found from the following expression:

$$
{ }^{1} S_{l}^{i}=S_{j}^{i} x_{l}^{j},
$$

where $\mathrm{x}_{1}^{\mathrm{j}}$ denotes industrial capacities needed to generate a set of resources $S_{l}^{i} ; S_{\mathrm{j}}^{i}$ is a matrix whose columns correspond to resources needed 


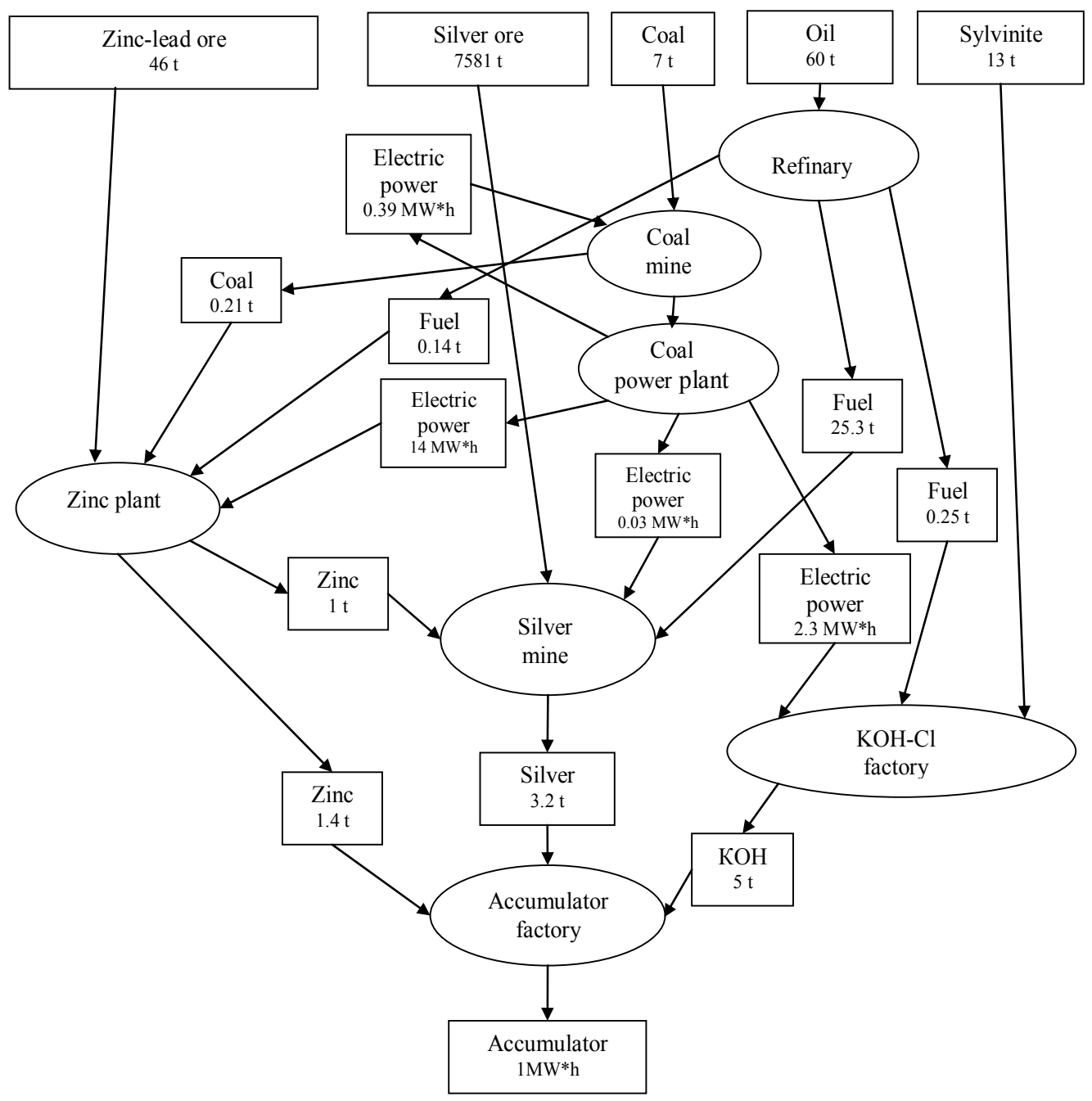

Fig. 11. A fragment of the tree of resources needed to create an Ag-Zinc battery

by the $j$-th industry to manufacture a unit of product. In the case of normalization of the needs matrix $S_{\mathrm{j}}^{i}$ to unity, vector $\mathrm{x}_{\mathrm{l}}^{\mathrm{j}}$ is explicitly expressed as follows:

$$
\begin{aligned}
& x_{i}^{j}=\varepsilon_{i}^{j} S_{l}^{i}, \\
& \varepsilon_{i}^{j}=\frac{1}{y_{i}^{j}},\left(y_{i}^{j} \neq 0\right), \\
& \varepsilon_{i}^{j}=0,\left(y_{i}^{j}=0\right),
\end{aligned}
$$

where $y_{i}^{j}$ is the amount of the $i$-th resource produced by the $j$-th industry per unit time, and $\varepsilon_{i}^{j}$ characterizes input-output relationships.
Thus, expression (14) can be written as follows:

$$
{ }^{1} S_{l}^{i}=S_{j}^{i} \varepsilon_{k}^{j} S_{l}^{k}
$$

However, as noted above, the production of resource vector ${ }^{1} S_{l}^{i}=S_{j}^{i} \varepsilon_{k}^{j} S_{l}^{k}$ also requires resources, and the need for them can be expressed from this vector similar to Eq.16. Thus, taking into account the $N$-th order indirect inputs, total resource inputs for the production, usage, and disposal of the product and, hence, the total environmental damage can be expressed as follows: 


$$
\begin{aligned}
& { }^{\Sigma} S_{l}^{i}=S_{l}^{i}+\sum_{n=1}^{N}\left(\left(S_{j}^{i} \varepsilon_{k}^{j}\right)^{n} S_{l}^{k}\right), \\
& R_{l}^{S}=a_{i}\left(S_{l}^{i}+\sum_{n=1}^{N}\left(\left(S_{j}^{i} \varepsilon_{k}^{j}\right)^{n} S_{l}^{k}\right)\right) .
\end{aligned}
$$

Matrix $S_{j}^{i} \varepsilon_{k}^{j}$ has the same meaning as the direct input matrix in the IOM (Leontief, 1973). Below is a simple example of calculating inputs of resources and the total environmental damage. To make the example more illustrative, we considered only four processes (an electric vehicle, a coal power plant (CPP), a metallurgical facility, and a coal mine) and four resources (electric energy, coal, metal, and petrol).

Suppose there is a 1.5-ton electric vehicle annually consuming 1 megawatt-hour of electric power, which has been used for three years. If the overage electric vehicle is not disposed of, total inputs for the production and usage of the vehicle per year are $S_{1}^{1}=1 \mathrm{MW}^{*}$ h of electric power and $S_{1}^{3}=0.5$ ton of metal. Electric energy is generated by the CPP, which consumes $S_{2}^{2}=0.35$ ton of coal to generate $1 \mathrm{MW}^{*} \mathrm{~h}$ of electric power. The metallurgical facility consumes $S_{3}^{1}=0.1 \mathrm{MW} * \mathrm{~h}$ of electric power and $S_{3}^{2}=0.5$ ton of coal to produce one ton of metal. The coalmine consumes $S_{4}^{1}=0.0006 \mathrm{MW}^{*} \mathrm{~h}$ of electric power and $S_{4}^{4}=0.003$ ton of fuel to mine 1 ton of coal. In this example, we ignore the input of resources to construct the CPP, the metallurgical facility, and the coalmine. Then the input matrix $S_{j}^{i}$ has the following form:

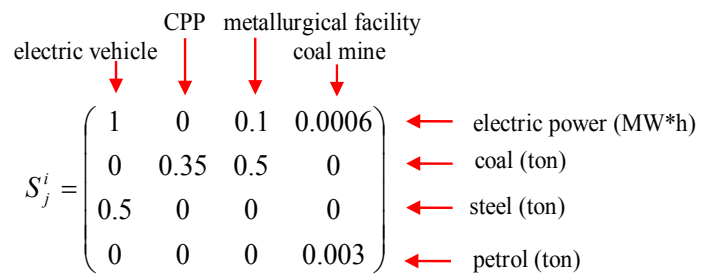

where the rows correspond to resources, and the columns to the processes in the above order. The matrix of links $\varepsilon_{i}^{k}$ has the form

$$
\varepsilon_{i}^{k}=\left(\begin{array}{cccc}
0 & 0 & 0 & 0 \\
1 & 0 & 0 & 0 \\
0 & 0 & 1 & 0 \\
0 & 1 & 0 & 0
\end{array}\right) .
$$

Calculation of the total resource consumption using Eq.17 can be given, for illustrative purposes, in expanded form:

$$
\begin{aligned}
& S_{\Sigma}^{i}=S_{1}^{i}+S_{j}^{i} \varepsilon_{i}^{k} S_{1}^{i}+S_{j}^{i} \varepsilon_{i}^{k} S_{j}^{i} \varepsilon_{i}^{k} S_{1}^{i}+ \\
& +S_{j}^{i} \varepsilon_{i}^{k} S_{j}^{i} \varepsilon_{i}^{k} S_{j}^{i} \varepsilon_{i}^{k} S_{1}^{i}=\left(\begin{array}{c}
1.05 \\
0.62 \\
0.5 \\
0.002
\end{array}\right) .
\end{aligned}
$$

In our example, the matrix of resources $S_{j}^{i}$ does not explicitly contain wastes of production plants. With this approach, environmental damage can be found by summing components of the total resource vector multiplied by the corresponding coefficients of the damage resulting from using resource $a_{i}$, such as carbon emissions from combustion of unit coal or petrol. Total average carbon emissions resulting from production and use of a vehicle in our example will be equal to:

$R_{1}^{S}=a_{i} S_{\Sigma}^{i}=\left(\begin{array}{llll}0 & 1 & 0 & 0.9\end{array}\right)\left(\begin{array}{c}1.05 \\ 0.62 \\ 0.5 \\ 0.002\end{array}\right)=0.6218$.

Comparison of the resource and environmental efficiency of gasoline and electric vehicles was performed under the following assumptions: a coal power plant is a source of electric power for the vehicle accumulator and for the construction of industrial facilities, mining of minerals, and production of accumulator components. Vehicles with engine power $50 \mathrm{~kW}$ are evaluated. The chosen gasoline consumption is $10 \mathrm{~L}$ for $100 \mathrm{~km}$. Only the power unit is taken into account; in this test, the vehicle itself is ignored; equal inputs are supposed to be expended on the production of the vehicle body, suspension, etc. The generalized parameter takes into account 
Table 1. Comparison of total inputs of resources and environmental damage for gasoline and electric vehicles with Ag-Zinc and lead-acid accumulators

\begin{tabular}{|c|c|c|c|}
\hline \multirow{2}{*}{ Resources needed for the vehicle to run for 1 hour } & \multicolumn{2}{|c|}{ Vehicle type (engine power 50 kW) } \\
\cline { 2 - 4 } & $\begin{array}{c}\text { Gasoline } \\
\text { vehicle }\end{array}$ & Electric vehicle \\
\cline { 2 - 4 } Labor force (human*hour) & 0.3 & 13.2 & 0.6 \\
Oil (ton) & 0.0122 & 0.0113 & 0.0002 \\
Coal (ton) & 0.0001 & 0.0252 & 0.0234 \\
Iron ore (ton) & 0.0000 & 0.0001 & 0.0000 \\
Non-ferrous metal ore (ton) & 0.0000 & 1.9068 & 0.0477 \\
Raw materials for construction industry (ton) & 0.0000 & 0.0003 & 0.0000 \\
Raw materials for chemical industry (ton) & 0.0000 & 0.0013 & 0.0000 \\
Carbon emission into atmosphere (kg) & 11 & 32 & 23 \\
\hline Air stream (m ${ }^{3} /$ hour) needed for dilution of toxic wastes & 8138 & 1012545 & 927613 \\
\hline
\end{tabular}

inputs used to construct and dispose of all facilities that have contributed to the production and taken part in the usage of the vehicles; the inputs are proportional to the contribution, which decreases towards primary resources. Results of the comparison are given in Table 1.

The results show quite clearly that the total environmental damage caused by the production, usage, and disposal of the vehicles is drastically different from the assessment declared by the advocates of electric vehicles, who are spreading the idea of their environmental safety. The result of the comparison was quite unexpected: carbon emissions to the atmosphere due to maintaining the operation of the electric vehicle are much greater than carbon emissions from the gasoline vehicle if indirect inputs of coal for the production of metal and electric energy are taken into account.

Thus, the use of the proposed approach can significantly change the assessments of environmental and economic efficiencies of certain goods and industrial processes. The formalism discussed in the study can be used to give an integrated evaluation of the environmental damage of a technology to be introduced. The proposed formalism takes into account factors that are not taken into account by the input-output theory because of the specific tasks of economics - the notion of the product was expanded to the notion of resource, including industrial wastes and primary natural resources (such as the area of fertile lands). Generalization of the concepts of the IOM made it possible to find a relationship between the production of goods necessary for the servicing of indirect inputs and the environmental damage caused by this production.

\section{Objective 3. Designing systems of optimal environmental management and adequate optimality criteria}

Let us now examine Objective 3, which becomes attainable after achieving Objective 1, i.e. determining resilience limits of the regional system, for which a system of optimal environmental management is being developed. At this stage, science can be of assistance, although playing less significant role than in the previous stages.

Let us take a simple example of optimization of environmental management (Bartsev et al., 
2001). Suppose there is a town with a workingage population of 1000 . Three different plants with parameters (in conventional units) given in Table 2 may be constructed and operated in this town. The question arises: What plants should be established in this town? To answer this question, we can use simple systems of extremum seeking, taking into account limitations. In the examples given below, we used the MS Excel "Solver" tool. The level of environmental safety was set as limitation on the variable to be optimized. As the target function to be maximized, we used the parameters given in each example.

The decision appears to depend on what is considered as important by the authorities of this town. For instance, if environmental concerns dominate, no plants will be constructed, and the citizens will have to find ways to survive on their own.

If, for example, the priority is to employ the citizens, keeping pollution at a predetermined level, the infrastructure of the town will be described by data in Table 3 .

If the authorities decide that the priority is to get maximum profit under conditions of full employment and keeping discharges at an environmentally safe level, the infrastructure is described by the data given in Table 4 .

If the authorities choose profit as the priority and decide to increase the permissible levels of pollution (to 7 conventional units) and to ignore the employment status of the citizens (allowing

Table 2. Parameters of plants

\begin{tabular}{|c|c|c|c|}
\hline Parameters per technological unit & Plant 1 & Plant 2 & Plant 3 \\
\hline Pollution level & 0.5 & 0.3 & 0.3 \\
\hline Number of employees & 50 & 200 & 50 \\
\hline Profit & 100 & 50 & 70 \\
\hline
\end{tabular}

Table 3. Infrastructure under conditions of full employment and environmental safety

\begin{tabular}{|c|c|c|c|c|}
\hline Parameters & Plant 1 & Plant 2 & Plant 3 & Constraints \\
\hline Number of units & 0 & 5 & 0 & No \\
Total pollution & 0 & 1.5 & 0 & 1.5 \\
Employed citizens & 0 & 1000 & 0 & 250 \\
Total profit & 0 & 250 & 0 \\
\hline
\end{tabular}

Table 4. Infrastructure under conditions of maximum profit, full employment, and environmental safety

\begin{tabular}{|c|c|c|c|c|}
\hline Parameters & Plant 1 & Plant 2 & Plant 3 & Constraints \\
\hline Number of units & 0 & 4.5 & 2.2 & No \\
Total pollution & 0 & 1.3 & 0.7 & 1000 \\
Employed citizens & 0 & 889 & 111 & 378 \\
Total profit & 0 & 222 & 156 \\
\hline
\end{tabular}


Table 5. Infrastructure under conditions of maximum profit, arbitrary employment, and neglecting environmental safety

\begin{tabular}{|c|c|c|c|c|}
\hline Parameters & Plant 1 & Plant 2 & Plant 3 & Constraints \\
\hline Number of units & 5 & 0 & 15 & No \\
Total pollution & 2.5 & 0 & 4.5 & 7 \\
Employed citizens & 250 & 0 & 750 & 1000 \\
Total profit & 500 & 0 & 1050 & 1550 \\
\hline
\end{tabular}

$70 \%$ unemployment), the infrastructure will be described by the data in Table 5 .

These calculations show that in management, the most important thing is to choose the priorities in making decisions on citizens' ways of living (Bartsev et al., 2012c). For instance, if environmental concerns become the only priority, there will be no production plants, and people will live in subsistence economy.

By prioritizing social stability, i.e. keeping unemployment at a socially safe level and maintaining pollution within predetermined limits, we obtain a different infrastructure of the region. If we add maximization of profit as a criterion, the infrastructure will change again.

If the authorities prioritize profit, raising permissible levels of environmental pollution (and living somewhere else) and caring little about social stability (and living even farther away), the infrastructure of economy will be completely different, and the lifetime of this infrastructure will be rather short.

\section{Conclusion}

Thus biospherics which can provide the basis for implementation of the concept of sustainable development, is necessarily an integrated science, which not only studies scientific aspects of the environmental crisis but also must take into account economic, social, moral, and other aspects of the life of humankind.

\section{Acknowledgements}

This work was supported by the program of the Presidium of RAS "Exploratory fundamental scientific research for the development of the Arctic zone (I.32)" No.0356-2016-0730.

\section{References}

Bartsev S.I., Degermendzhi A.G., Belolipetsky P.V. (2012a) Carbon cycle modeling and principle of the worst scenario. Models of the ecological hierarchy: from molecules to the ecosphere. Jordan F., Jorgensen S.E. (eds.) Elsevier, p. 447-458

Bartsev S.I., Degermendzhi A.G., Erokhin D.V. (2008) Principle of the worst scenario in the modelling past and future of biosphere dynamics. Ecological Modeling, 216: 160-171

Bartsev S.I., Degermendzhi A.G., Okhonin V.A., Saltykov M.Y. (2012b) An integrated approach to the assessment of an ecological impact of industrial products and processes. Procedia Environmental Science, 13: 837-846

Bartsev S.I., Ivanova Y.D., Shchemel A.L. (2012c) The worst scenario principle and the assessment of the impact of quality of life for biosphere dynamics. Models of the ecological hierarchy: from molecules to the ecosphere. Jordan F., Jorgensen S.E. (eds.) Elsevier, p. 459-467

$$
-151-
$$


Bartsev S.I., Mezhevikin V.V., Okhonin V.A. (2001) The principle of closure and criteria for optimal environmental management and sustainable development. Chemistry for Sustainable Development, 9: 805-814 (in Russian)

Brovkin V., Bendsen J., Claussen M., Ganapolski A., Kubatzki C., Petoukhov V., Andreev A. (2002) Carbon cycle, vegetation, and climate dynamics in Holocene: experiments with the CLIMBER-2 model. Global Biogeochemical Cycles, 16: 1139-1143

Brovkin V., Sitch S., Bloh von W., Claussen M., Bauer E., Cramer W. (2004) Role of land cover changes for atmospheric $\mathrm{CO} 2$ increase and climate change during the last 150 years. Global Change Biology, 10: 1253-1266

Degermendzhi A.G., Bartsev S.I., Gubanov V.G., Erokhin D.V., Shevirnogov A.P. (2008) Forecast of biosphere dynamics using small-scale models. Global climatology and ecodynamics: anthropogenic changes to planet earth. Cracknell A.P., Krapivin V.F. (eds.) Springer Praxis Books, Berlin, p. 241-300

Eberhard M. (2009) Tesla Motors, California ARB ZEV Symposium. https://www.arb.ca.gov/ msprog/zevprog/2006symposium/presentations/eberhard.pdf

Gifford R.M. (1993) Implications of CO2 effects on vegetation for the global carbon budget. The Global Carbon Cycle. Heimann M. (ed.) Springer-Verlag, Berlin, p. 159-199

IPCC (2001) Climate Change 2001: The Scientific Basis. Contribution of Working Group I to the Third Assessment Report of the Intergovernmental Panel on Climate Change. Houghton J.T., Ding Y., Griggs D.J., Noguer M., van der Linden P.J., Dai X., Maskell K., Johnson C.A. (eds.) Cambridge University Press, Cambridge, United Kingdom and New York, NY, USA, 881 p.

IPCC (2007) Climate Change 2007: The Physical Science Basis. Contribution of Working Group I to the Fourth Assessment Report of the Intergovernmental Panel on Climate Change. Solomon S., Qin D., Manning M., Chen Z., Marquis M., Averyt K.B., Tignor M., Miller H.L. (eds.) Cambridge University Press, Cambridge, United Kingdom and New York, NY, USA, 996 p.

IPCC (2014) Climate Change 2014: Synthesis Report. Contribution of Working Groups I, II and III to the Fifth Assessment Report of the Intergovernmental Panel on Climate Change. Core Writing Team, Pachauri R.K., Meyer L.A. (eds.) IPCC, Geneva, Switzerland, 151 p.

Kondratiev K.Ya., Krapivin V.F. (2004) Carbon global cycle modeling. Moscow, Fizmatlit, 336 p. (in Russian)

Leontief W. (1973) Structure of the world economy (Outline of a Simple Input-Output Formulation), Nobel Memorial Lecture. http://laprimaradice.myblog.it/media/00/02/2730068406.pdf

Pechurkin N. (1994) Biospherics: a new science. Life Support \& Biosphere Science, 1(2): 85-87

Rio (1992) The Rio declaration on environment and development/ http://www.unesco.org/ education/pdf/RIO_E.PDF

Semenov S.M. (2004) Greenhouse gases and present climate of the Earth. Moscow, Meteorology and Hydrology Publishing Centre, 175 p. (in Russian)

Trenberth K.E., Houghton J.T., Meira Filho L.G. (1996) The Climate System: an overview. Climate Change 1995. The Science of Climate Change. Houghton J.T., Meira Filho L.G., Callander B.A., Harris N., Kattenberg A., Maskell K. (eds.) Cambridge University Press, Cambridge, p. 51-64 